\title{
Effect of Interlayer Cooling on the Preparation of Ni-Based Coatings on Ductile Iron
}

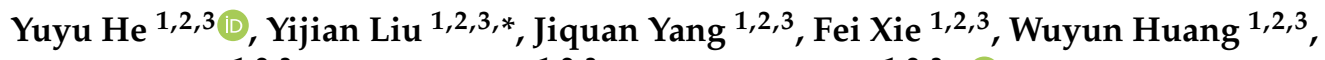 \\ Zhaowei Zhu ${ }^{1,2,3}$, Jihong Cheng ${ }^{1,2,3}$ and Jianping Shi ${ }^{1,2,3, *(D)}$ \\ 1 School of Electrical and Automation Engineering, Nanjing Normal University, Nanjing 210023, China; \\ 171802031@stu.njnu.edu.cn (Y.H.); 63047@njnu.edu.cn (J.Y.); xiefei@njnu.edu.cn (F.X.); \\ 171835010@stu.njnu.edu.cn (W.H.); 181802030@stu.njnu.edu.cn (Z.Z.); 63029@njnu.edu.cn (J.C.) \\ 2 Jiangsu Key Laboratory of 3D Printing Equipment and Manufacturing, Nanjing 210023, China \\ 3 Nanjing Institute of Intelligent High-End Equipment Industry Co. Ltd., Nanjing 210023, China \\ * $\quad$ Correspondence: 61213@njnu.edu.cn (Y.L.); jpshi@njnu.edu.cn (J.S.); Tel.: +86-02585481135 (Y.L.); \\ +86-02585481135 (J.S.)
}

Received: 25 March 2020; Accepted: 27 May 2020; Published: 4 June 2020

\begin{abstract}
In metal additive manufacturing without interlayer cooling, the macro-size of the layer itself is difficult to control due to the thermal storage effect. The effect of interlayer cooling was studied by cladding Ni-based coatings on the substrate of ductile iron. The results show that under the same process parameters, compared with non-interlayer cooling deposition, the dilution rate is better, and the thickness increase of interlayer cooling deposition is more uniform, which is conducive to controlling the macro-size of the interlayer cooling deposition. Furthermore, interlayer cooling deposition has fewer impurities and more uniform microstructures. Moreover, the average grain size is refined and the dendrite growth is inhibited, which improves the mechanical properties of the coating. Therefore, the hardness of the interlayer cooling specimens is greater than that of the non-interlayer-cooled specimens.
\end{abstract}

Keywords: metal additive manufacturing; nickel-based alloy; microstructure; cooling effect

\section{Introduction}

Ductile iron possesses the properties of high strength, toughness, wear resistance, shock absorption, easy cutting, notch insensitive, etc. However, due to the harsh working conditions, the surface wear of ductile iron can cause mechanical failure [1,2]. Surface modification technology is an effective way to enhance surface strengthen, overcome the limitations of shape and size, and reduce costs [3]. Due to its good properties and low cost, Ni-based powders are often used to improve the surface properties of substrates, such as strength, wear resistance, and corrosion resistance [4-6].

Mughal et al. [7,8] used the finite element method to study the process of metal additive manufacturing process. It has been proven that continuous deposition without interlayer cooling leads to high and uniform preheating of the substrate, which reduces the deformation of the cladding layer. However, at the same time, it was found that the continuous multilayer deposition causes a thermal storage effect, which results in the loss of control over dimensional tolerances.

Delinger et al. [9] studied the effect of interlayer cooling time on the distortion and residual stress of Ti-6Al-4V powder. The results show that a shorter interlayer cooling time produces lower distortion and residual stresses. Nevertheless, shortening the cooling time can excessively increase the energy input into the system. Overheating can consequently lead to undesirable remelting, poor surface finish, and poor dimensional tolerances in the final part. 
Chen et al. [10] studied the effect of improving the base cooling effect on the metal additive manufacturing process. It is found that the crystal orientation of the specimens can be improved by imposing a continuous water flow on the back of the substrate. As described in the paper, due to the thermal storage during the deposition process, the microstructure of the deposition is uneven. This means that as the number of layers increases, the cooling effect becomes worse. Furthermore, it is only suitable for specimens with simple shapes, not for specimens with complex shapes.

At present, there are many studies on laser process parameters. Weng et al. [11] studied the effects of laser-specific energy on the microstructures and properties of the cladding layers. Liu et al. [12] compared the structural and mechanical properties of Inconel 718 prepared with or without argon protection during laser cladding. Cheng et al. [13] studied the effects of laser energy density and scanning speed on the properties of the cladding layer. However, few studies have been done on the effect of interlayer cooling. In this paper, the differences in the microstructure and properties of two Ni-based alloys deposited on ductile iron under interlayer cooling or non-interlayer cooling conditions were investigated. This work can improve the quality of the cladding layer, especially strength and hardness, and help control dimensional tolerances.

\section{Experimental Details}

The experimental system consists of a $4 \mathrm{~kW}$ semiconductor laser (LDM 4000-100, Laserline, Mülheim-Kärlich, Germany), a 6-axis KUKA robot (KR 16-2), a high precision powder feeder, a side powder feeding nozzle, and an inert gas (Ar) protection box.

The substrate was a piece of ductile iron (ISO 1038/JS/500-7) with a size of $100 \mathrm{~mm} \times 50 \mathrm{~mm} \times$ $15 \mathrm{~mm}$. The powder used in the experiment was Ni-based self-fluxing alloy powder (Wall Colmonoy Corporation, Madison Heights, MI, USA). The chemical compositions of the ductile iron and the powder are listed in Tables 1 and 2, respectively.

Table 1. Chemical composition of ductile iron (mass fraction (\%)).

\begin{tabular}{ccccccc}
\hline $\mathbf{C}$ & $\mathbf{S i}$ & $\mathbf{M n}$ & $\mathbf{S}$ & $\mathbf{P}$ & $\mathbf{M g}$ & $\mathbf{R e}$ \\
\hline $3.55-3.85$ & $2.34-2.86$ & $<0.6$ & $<0.025$ & $<0.08$ & $0.02-0.04$ & $0.03-0.05$ \\
\hline
\end{tabular}

Table 2. Chemical composition of cladding materials (mass fraction (\%)).

\begin{tabular}{ccccccc}
\hline Al & B & C & Cr & Fe & Si & Ni \\
\hline 1.1 & 1.0 & 0.14 & 3.5 & 2.0 & 2.7 & Rem \\
\hline
\end{tabular}

Before the experiment, the powder was dried in a vacuum at $100{ }^{\circ} \mathrm{C}$ for $2 \mathrm{~h}$ to remove water vapor adsorbed on the surface. The substrate's surface was polished with sandpaper (180-400 grit sandpaper) and cleaned with acetone. The main process parameters used in the experiments are as follows: laser power of 1.6-2.5 kW, scanning speed of $8 \mathrm{~mm} / \mathrm{s}$, powder feeding speed of $20 \mathrm{~g} / \mathrm{min}$, gas flow rate of $12 \mathrm{~L} / \mathrm{min}$, laser spot diameter of $5 \mathrm{~mm}$, and deposition thickness of $0.2 \mathrm{~mm}$. Table 3 shows the deposition parameters in the experiment. After each cladding layer was completed, each interlayer cooling specimen was cooled to room temperature (about $5 \mathrm{~min}$ ), and each non-interlayer cooling specimen was cladded without waiting time. The cladding equipment and one of the samples are shown in Figure 1. 
Table 3. Experimental parameters, thickness of layers, and depth of penetration.

\begin{tabular}{cccccc}
\hline No. & $\begin{array}{c}\text { Laser } \\
\text { Power }(\mathbf{W})\end{array}$ & $\begin{array}{c}\text { Number of } \\
\text { Cladding Layers }\end{array}$ & $\begin{array}{c}\text { Does it Include } \\
\text { Cooling Time }\end{array}$ & $\begin{array}{c}\text { Thickness of } \\
\text { Layers }(\mathbf{m m})\end{array}$ & $\begin{array}{c}\text { Penetration }(\boldsymbol{\mu m}) / \\
\text { Dilution Rate }(\%)\end{array}$ \\
\hline 1 & 1600 & 10 & No & 9.52 & $156 / 1.55$ \\
2 & 1600 & 10 & Yes & 10.01 & $149 / 1.67$ \\
3 & 2000 & 8 & No & 6.25 & $630 / 9.16$ \\
4 & 2000 & 8 & Yes & 8.01 & $714 / 8.18$ \\
5 & 2500 & 8 & No & 5.88 & $564 / 8.62$ \\
6 & 2500 & 8 & Yes & 6.92 & $625 / 8.28$ \\
\hline
\end{tabular}

The height of the cladding layers was measured by a micrometer. The cross-section of the specimen was cut by a wire-cut electrical discharge machine (EDM, DK7763, CHENGHONG, Jiangsu, China) along a vertical laser path. Metallographic specimens were prepared by mechanical polishing. The polished specimens were etched by a solution $\left(200 \mathrm{~mL} \mathrm{H}_{2} \mathrm{O}+200 \mathrm{~mL} \mathrm{HCl}+40 \mathrm{~g} \mathrm{CuSO}_{4}\right)$. The heat-affected zone (HAZ) was etched by a solution ( $\mathrm{HF}$ and $\mathrm{HNO}_{3}$ 1:1 mixing). The microstructures of the powder and the layers were analyzed by optical microscopy (OM, Axio Vert.A1, ZEISS, Oberkochen, Germany), and a scanning electron microscopy (SEM, SIGMA 04-03, ZEISS, Oberkochen, Germany) equipped with an energy-dispersive spectroscopy (EDS). The penetration data in Table 3, which indicate the distance from the deepest position of the substrate's melting part to the surface of the substrate, as schematically illustrated in Figure 2, were also measured by an optical microscopy. Meanwhile, the dilution ratio in Figure 2 is the ratio of penetration to thickness of layers. Phase constitution was identified by X-ray diffraction (XRD, D/MAX 2500/PC, Neo-confucianism, Tokyo, Japan). The microhardness of the single tracks was measured with a HV-5ACL microhardness tester (HENGYI, Shanghai, China) and a Vickers pyramidal-shaped diamond indenter under the load of $0.5 \mathrm{~kg}$ for $15 \mathrm{~s}$ of loading.

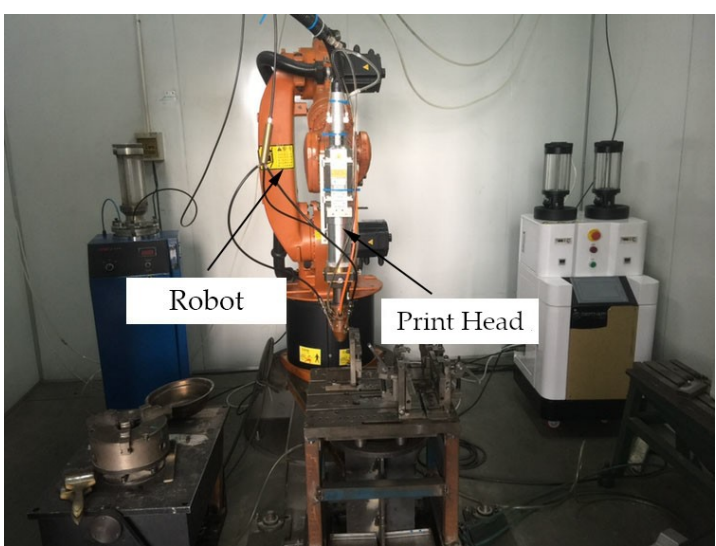

(a)

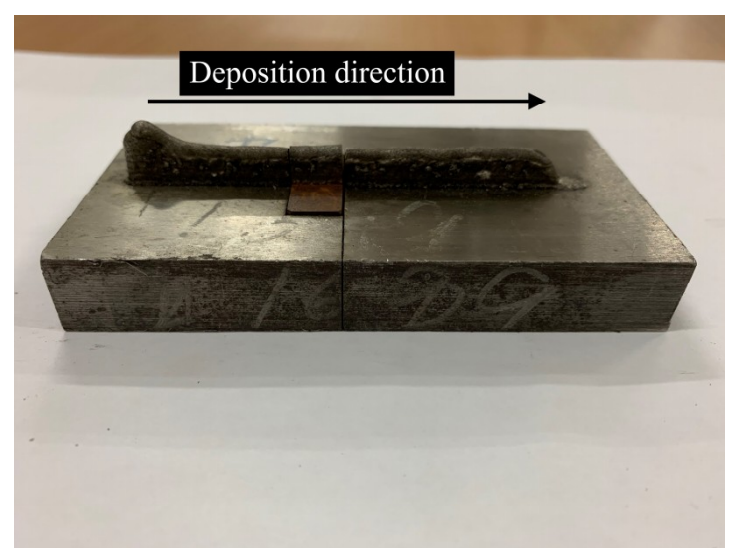

(b)

Figure 1. Pictures of the cladding equipment and specimens: (a) cladding equipment; (b) picture of one specimen. 


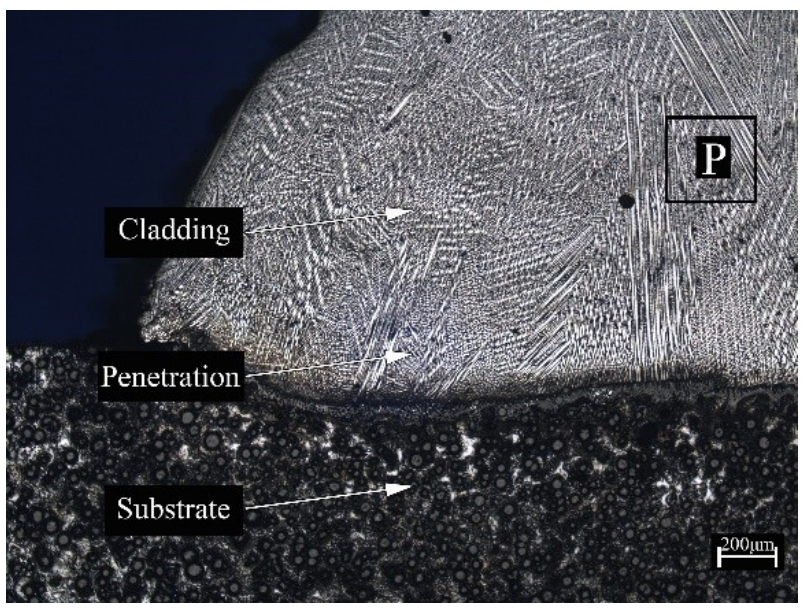

Figure 2. Overview of the cladding.

\section{Results and Discussion}

Figure 3 a shows that the powder particles are regular spheres of 50-100 $\mu \mathrm{m}$, which helps the smooth powder transfer during the deposition process. Figure $3 b$ (the XRD pattern of the powder) shows that the main phase of the powder is $\gamma-\mathrm{Ni}$.

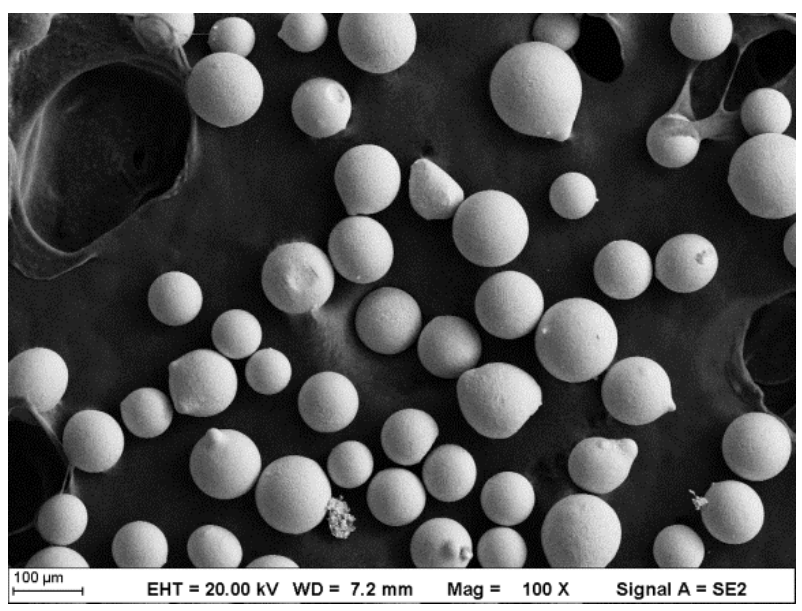

(a)

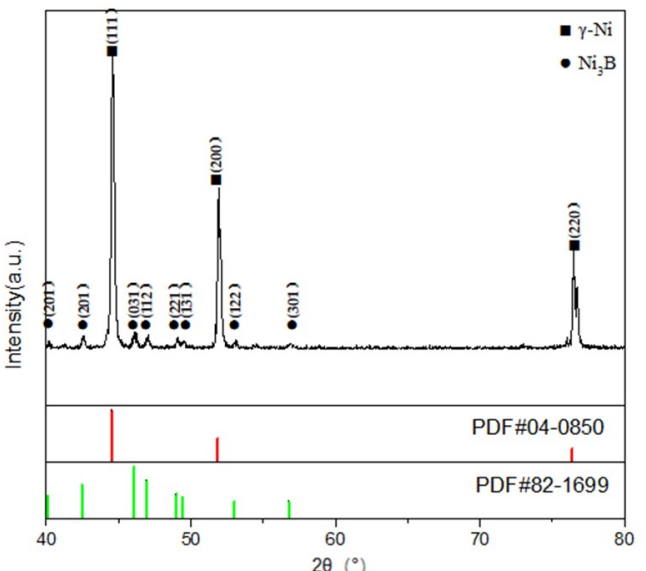

(b)

Figure 3. SEM image and XRD patterns of the powder: (a) SEM image of powder shape and size and (b) XRD pattern of the powder.

Figure 2 shows a schematic overview image of the cladding. There are no pores or cracks in the coating. Planar growth at the interface between the coating/substrate indicates good metallurgical bonding. The micromorphologies of the six specimens in Table 3 are shown in Figure 4. Their corresponding areas are in the middle of the samples (Area P in Figure 2). There are some bright and black impurities in coatings, as shown in Figures 4 and 5. Compared to the non-interlayer cooling specimens, the interlayer cooling specimens have less impurities. Through SEM and EDS results (Figure 6), the contents of Fe and $\mathrm{Al}$ in the bright impurities are $6.8 \%$ and $9.4 \%$, respectively, which are higher than the normal values. Meanwhile, the contents of $\mathrm{O}$ and $\mathrm{Cl}$ are more than $20 \%$ in the black impurities. This may be due to the reaction between the black impurities and $\mathrm{HCl}$ during sample preparation. Hence, the bright impurities in Figure 4c may be the intermetallic compounds of $\mathrm{Al}$, and the black impurities in Figure 4a may be oxides. 


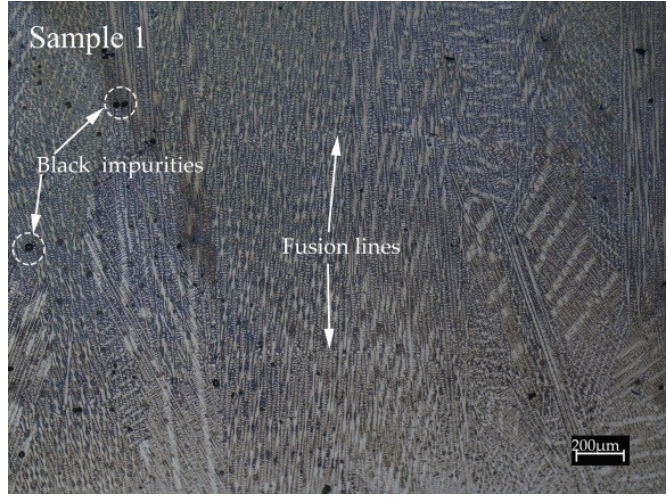

(a)

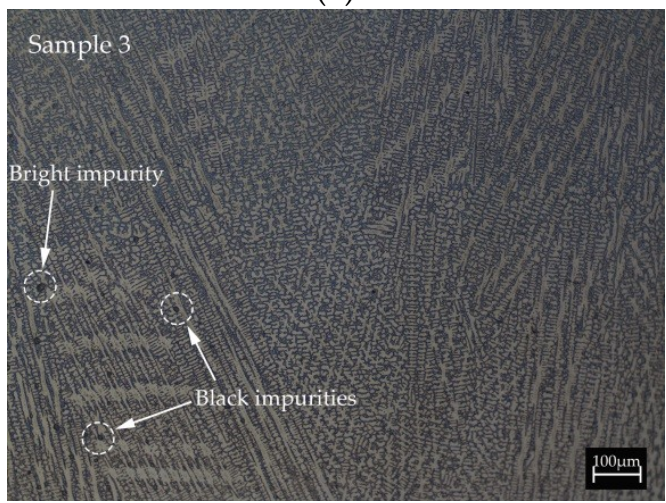

(c)

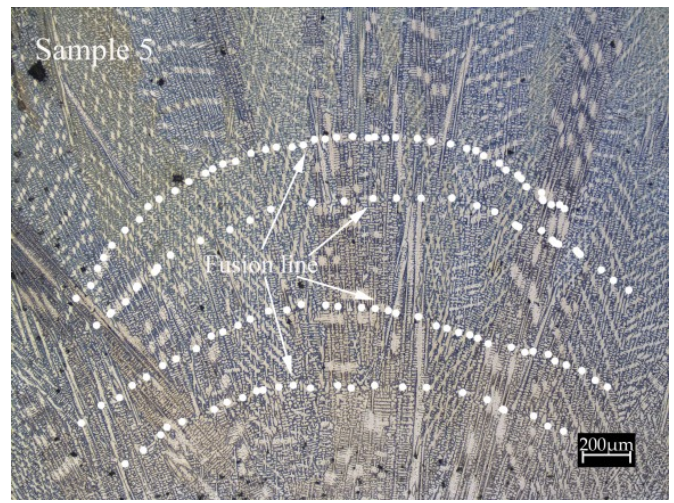

(e)

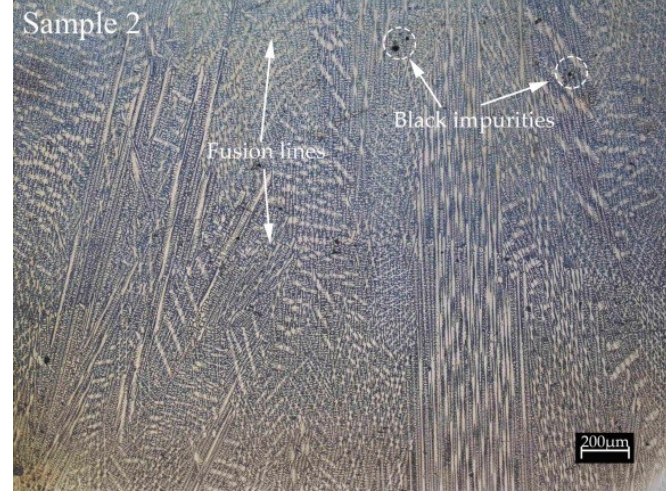

(b)

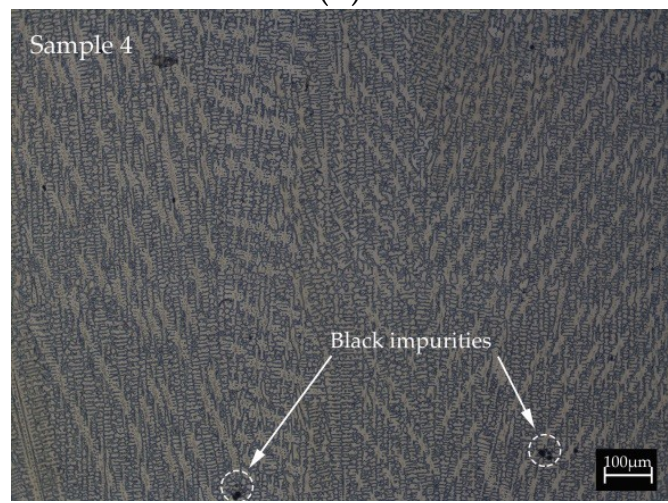

(d)

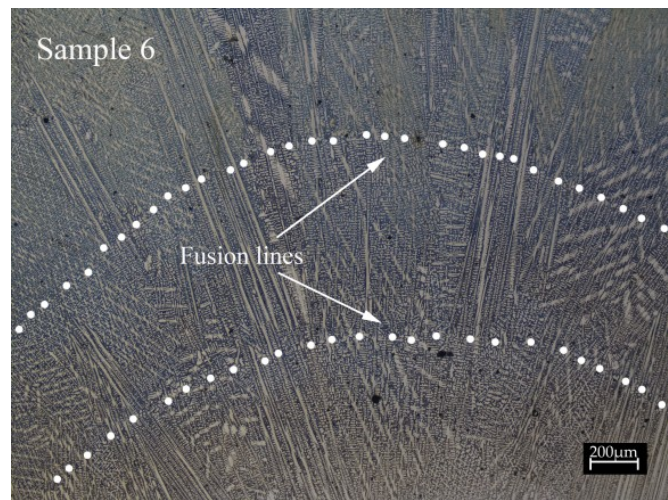

(f)

Figure 4. Optical microscopy (OM) images of 6 groups about fusion lines and impurities: (a) fusion lines and black impurities in Sample 1; (b) fusion lines and black impurities in Sample 2; (c) bright and black impurities in Sample 3; (d) black impurities in Sample 4; (e) fusion lines in Sample 5; and (f) fusion lines in Sample 6.

During the deposition process, the pre-deposited layer acts as a substrate. At the bottom of the molten pool, the low-melting eutectic compounds in the interdendritic region were remelted; then, they diffused into the molten pool and diluted the composition of the interdendritic liquid [14]. After that, the interdendritic liquid was restored to a composition suitable for dendritic growth. As a result, the un-remelted dendrite arms grew slightly larger than the dendrites in the surrounding area, which produced metallographical details of the fusion lines in the optical micrograph, as shown in Figure $4 \mathrm{a}, \mathrm{b}$. The fusion of each layer in Sample 5 and Sample 6 is highlighted by the white dashed lines in Figure 4e,f, respectively. Figure 7 shows a further enlarged detail of the fusion lines, which clearly shows the fusion lines produced by remelting. Due to the high energy input of laser, according to the 
metallographic diagram, part of the pre-deposited layer was remelted into the lower layer during the deposition of each layer. Therefore, the size of the molten pool is increased.

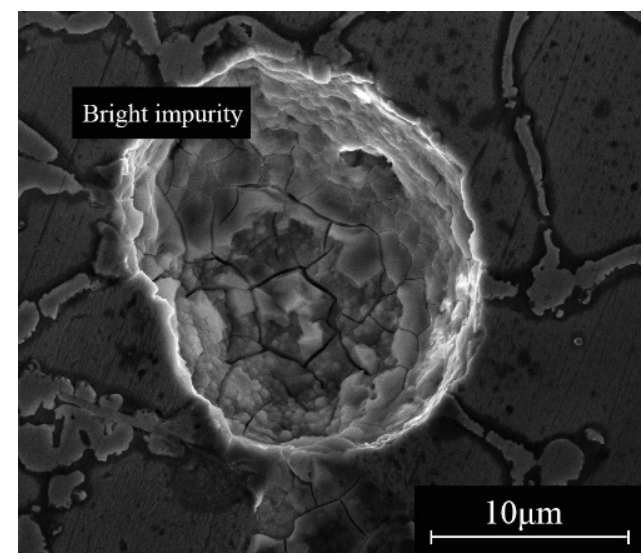

(a)

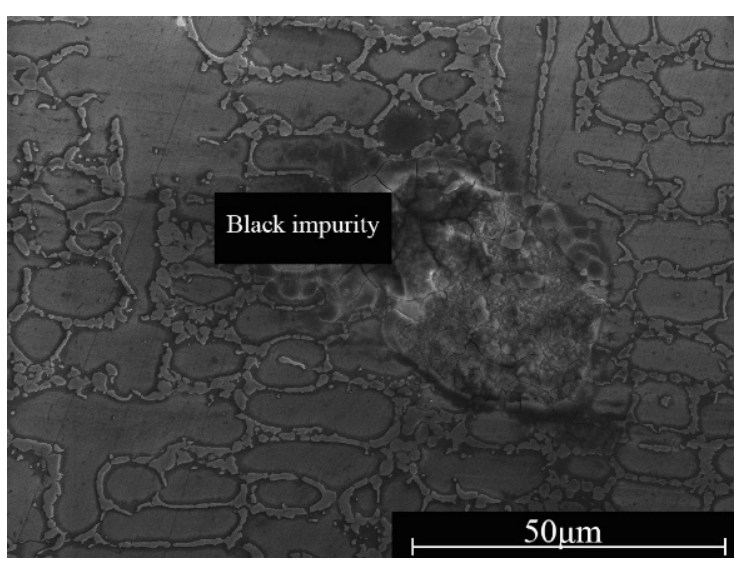

(b)

Figure 5. SEM images of the impurities: (a) bright impurity; (b) black impurity.
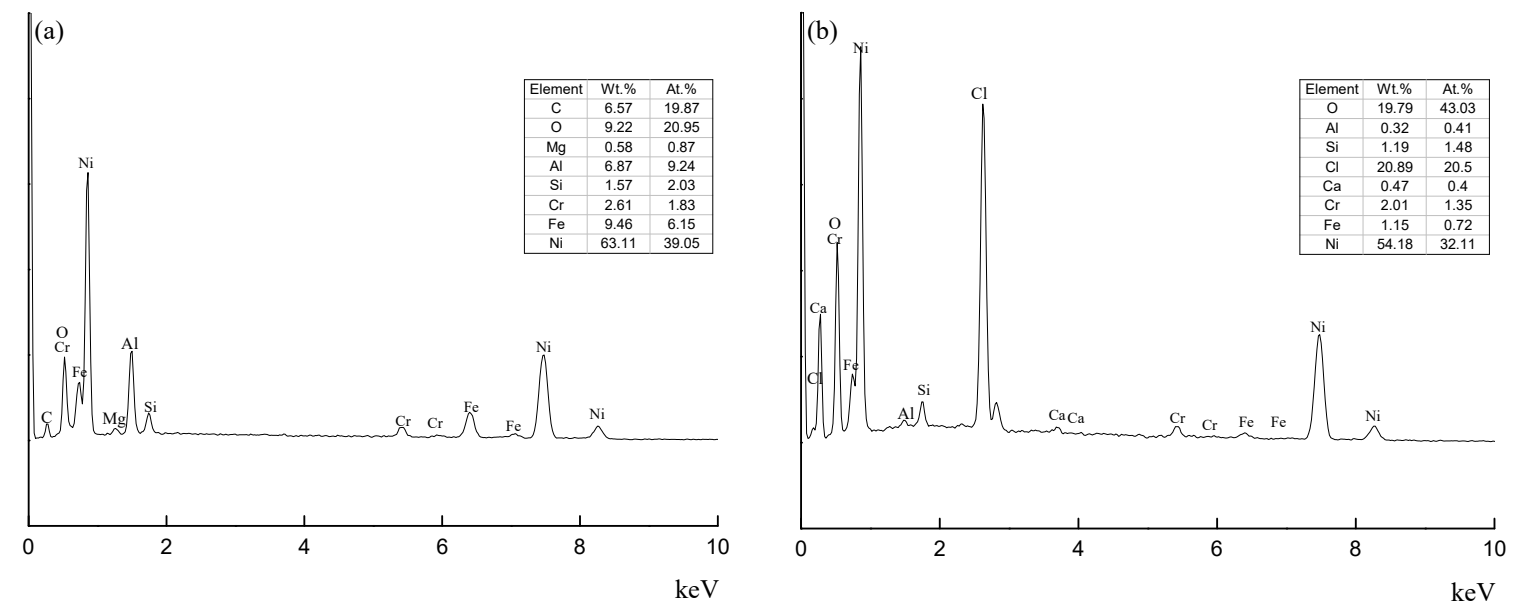

Figure 6. Energy-dispersive spectroscopy (EDS) results for the bright impurities (a) and black XRD impurities (b).

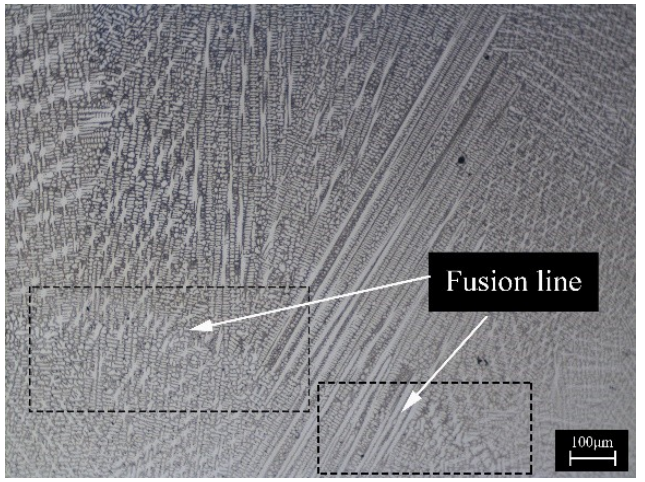

(a)

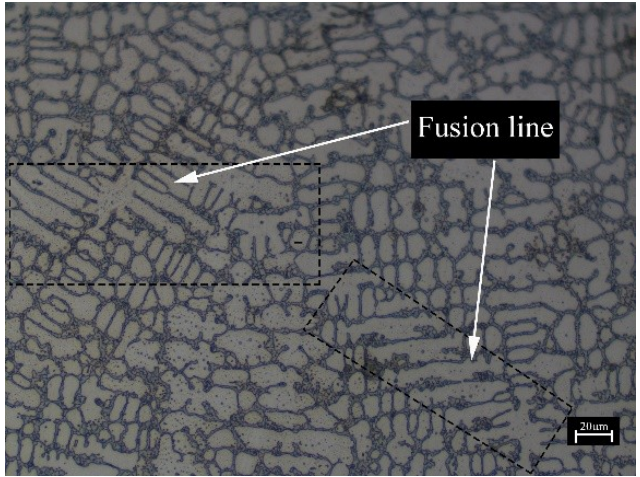

(b)

Figure 7. The detail of fusion line at $100 \times$ magnification (a) and at $400 \times$ magnification (b).

Compared with the interlayer cooling specimens, non-interlayer cooling deposition was preheated excessively due to heat storage effect, which caused the temperature of the molten pool to rise. Thus, the control of the dilution rate and the dimensional tolerance of the non-interlayer cooling deposition 
become harder $[6,15,16]$. Moreover, excessive preheating makes each layer of the non-interlayer cooling specimen thinner and the final layer thicker. As shown in Table 3, with the same process parameters, the thickness of the layers without cooling is slightly smaller than that with cooling. This is because the poor thermal conductivity of nickel causes heat buildup in the layer, which increases the diameter of the molten pool. The higher the temperature of the pre-deposited layer, the larger the molten pool will be. The larger size of the molten pool will form a cladding layer with a smaller thickness and a larger width. By comparing the specimens with and without interlayer cooling, the interlayer cooling specimens have a greater penetration depth but a smaller dilution rate. Sample 1 and Sample 2 were not considered because their penetration depths were too small to be representative. In order to ensure the high performance of the cladding layer, it is generally considered that the dilution rate should be less than $10 \%$, preferably about $5 \%$ [17]. Furthermore, the direction of dendrite growth in the non-interlayer cooling specimens is more chaotic. This is due to the preheating of the substrate, which makes it difficult to dissipate heat, thereby making the dendrites grow disorderly.

Figure 8 shows high magnification micrographs of Sample 5 and Sample 6. Due to the high cooling rate, the typical rapid directional solidified structures composed of dendritic and interdendritic regions are shown. In contrast, the number of primary dendrites and secondary dendrites in the cladding specimens with interlayer cooling was significantly higher than that in the specimen without cooling. The smaller the number of dendrites per unit area, the greater the distance between the dendrites. According to the solidification theory, the dendrite spacing depends on the heat dissipation condition at the solidification interface. The stronger the heat dissipation ability, the smaller the influence range of the latent heat of the crystals precipitated from each branch, and the smaller the dendrite spacing. When directional solidification occurs, the cooling rate is determined by the heat dissipation capacity at the solid-liquid interface. The greater the cooling rate, the stronger the heat dissipation capability at the solid-liquid interface. Therefore, a high solidification rate often leads to fine dendrite arrangement. Interlayer cooling facilitates heat dissipation during deposition and provides faster cooling rates. Some studies have shown that at higher cooling rates, dendrite coarsening is inhibited, dendrite spacing decreases, nucleation rate increases, and the grain refinement and interfacial base increase $[18,19]$, which prevent dislocation movement, balance plastic deformation, and increase the strength of the coating [20-22].

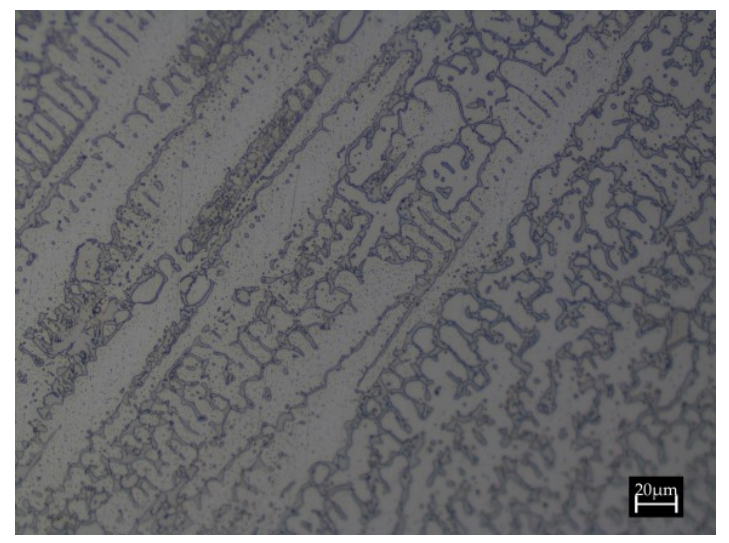

(a)

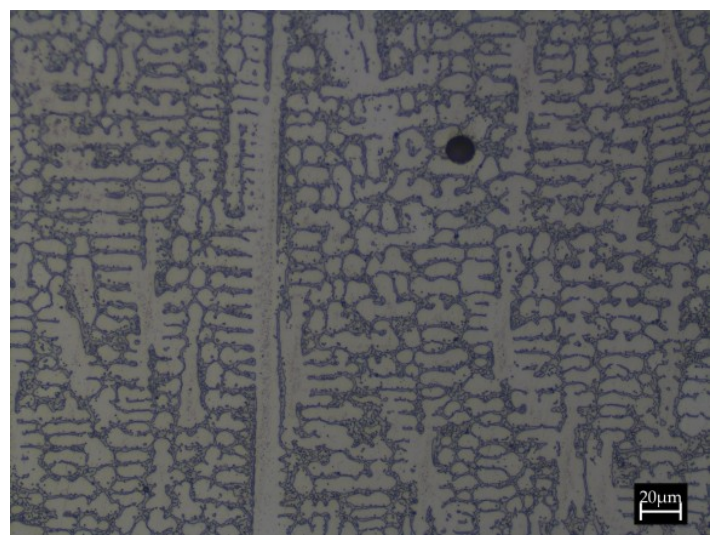

(b)

Figure 8. Dendritic images of Sample 5 (a) and Sample 6 (b).

Since the constituent phases cannot be identified by optical microscopy, further SEM and EDS analyses were performed on the cladding layers. Figure 9 is a representative SEM image of Sample 5. Typical dendritic structures, including dendritic and interdendritic regions, can be clearly seen in the figure. Combine with the EDS results in Figure 10, it is judged that area $\mathrm{A}$ is the $\gamma$ phase and area $\mathrm{B}$ is the $\gamma^{\prime}$ phase. 


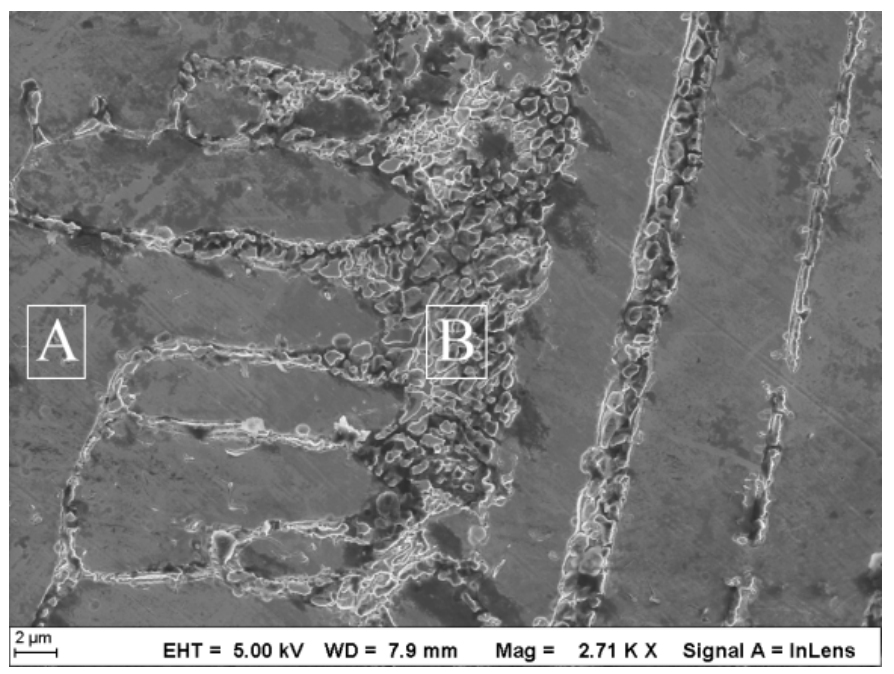

Figure 9. SEM image of cross-section morphology of Sample 5 coating.
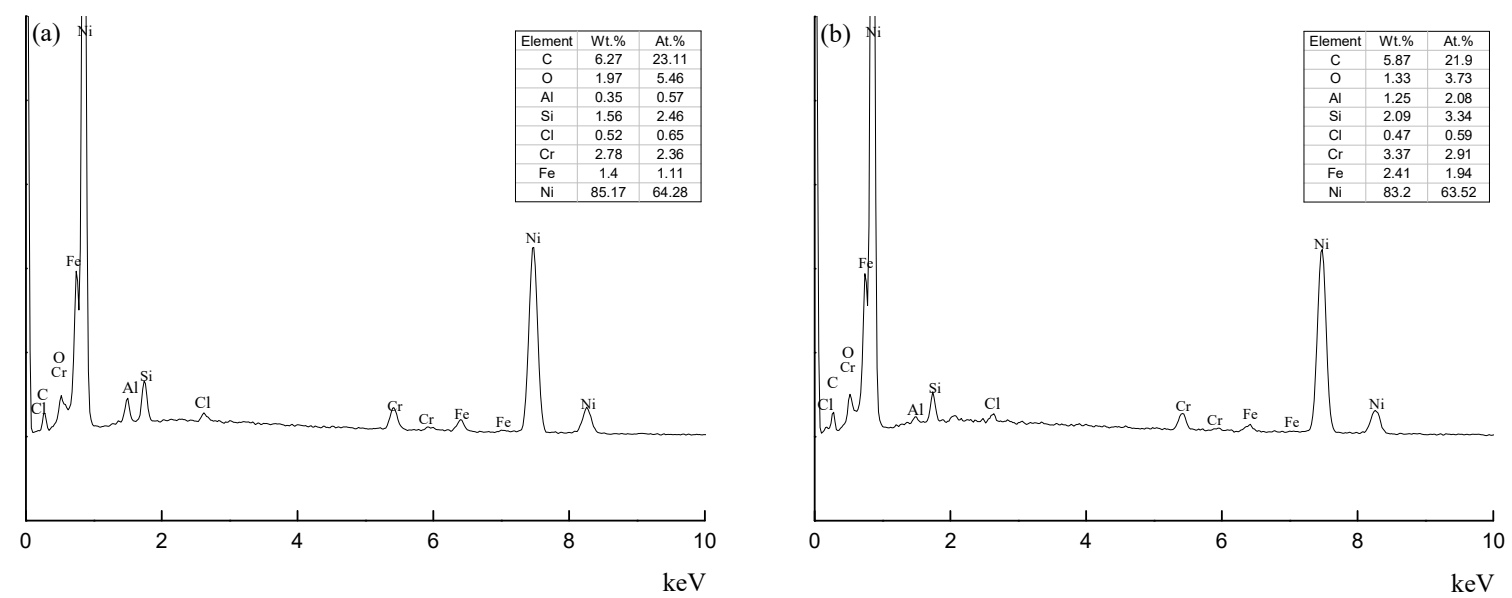

Figure 10. EDS results for area A (a) and area B (b).

To further determine the composition, six sets of specimens were analyzed by $\mathrm{XRD}$, as shown in Figure 11. Sharp and broad peaks were observed, which corresponded to the $\gamma$ and $\gamma^{\prime}$ phase of the Ni-base solid solution. $\mathrm{Ni}_{3} \mathrm{~B}$ phase and some other compounds of $\mathrm{Ni}$ were observed in Samples 1 and 2. Combined with the XRD pattern of the powder (Figure 3b), it may be due to insufficient laser power, resulting in more Ni3B residue powder in the coatings. At the same time, $\mathrm{NiC}_{x}$ was created. From the XRD results, no significant intermetallic oxides were observed due to the low volume fraction.

The grain sizes of in Figure 11 were calculated by Scheler's formula. The grain sizes of samples 1-6 are 33.2, 28.7, 56.7, 36.9, more than 100 and $39.5 \mathrm{~nm}$, respectively. By comparing Samples 1, 3, and 5 or Samples 2, 4, and 6, we can find that the grain sizes of the sample increase with the increase of laser power. This is due to the temperature of molten pool increasing with the increase of laser power. However, there is no obvious difference in the increase of grain sizes of the samples with interlayer cooling, only from 28.7 increase to $39.5 \mathrm{~nm}$, while the grain sizes of non-interlayer cooling change greatly, from 33.2 to more than $100 \mathrm{~nm}$. 


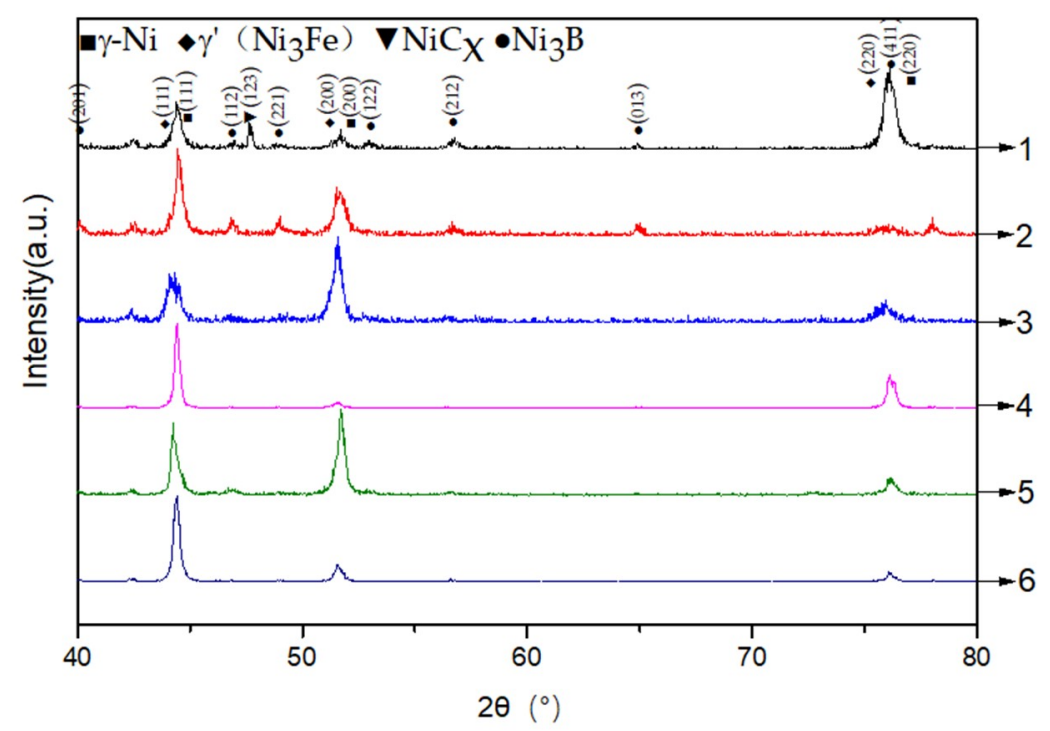

Figure 11. Diffraction patterns of 6 groups of single tracks.

Furthermore, by comparing Sample 1 and 2, there is no significant difference between the grain sizes of them, which shows that the effect of interlayer cooling on the grain size is small at the laser power of $1.6 \mathrm{~kW}$. Nevertheless, with the increase of laser power, the difference of grain size becomes more and more significant. Especially when the laser power is $2.5 \mathrm{~kW}$, the grain size of the samples without interlayer cooling is more than twice that of the samples with interlayer cooling. This shows that the effect of interlayer cooling will be improved with the increase of laser power.

The microhardness distribution from the top of the coatings to the substrate are shown in Figure 11. It indicates that the average microhardness of the cladding layer increases from $263 \pm 8.5 \mathrm{HV}_{0.5}$ to $335 \pm 6.9 \mathrm{HV}_{0.5}$. Under the same process parameters, the average microhardness of the specimens with and without interlayer cooling does not change significantly near the surface of the substrate due to the interaction between the cladding layer and the substrate. In Figure 12a, there is no significant difference in microhardness between Samples 1 and 2, especially near the surface of the substrate. This is due to the lower laser power and insufficient thermal input. As a result, the remelting area of the pre-deposited layer is less. In this area, the interlayer cooling effect is not significant, and the lower the power, the larger the area. As the distance increases, the average microhardness of the specimens with interlayer cooling begins to be higher than that of the specimen without interlayer cooling. By comparing the microhardness of the two samples in Figure 12a-c, we can find that the microhardness difference is more and more significant with the increase of laser power. The microhardness of the same thickness exceeds $3-4 \%$ in Figure $12 b$, while that exceeds $6-8 \%$ in Figure 12c. This is due to the poor thermal conductivity of Ni-based metals. As deposits accumulate, the heat dissipation effect decreases gradually, resulting in heat accumulation and relative preheating of the substrate. The better heat dissipation makes the grain size of the interlayer cooling specimens relatively fine and uniform and increases the total area of the grain boundaries, thereby preventing dislocation movement, balancing plastic deformation, and improving the strength of the coating. When the laser power is low (Figure 12a), the influence is insignificant. With the increase of laser power, there is a significant difference between the two grain sizes, leading to a significant difference between the two conditions. This shows that with the increase of laser power, the effect of interlayer cooling will become more and more significant. 


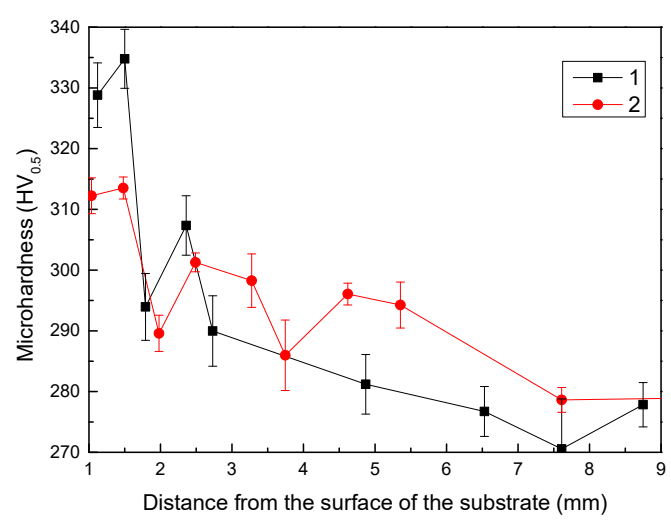

(a)

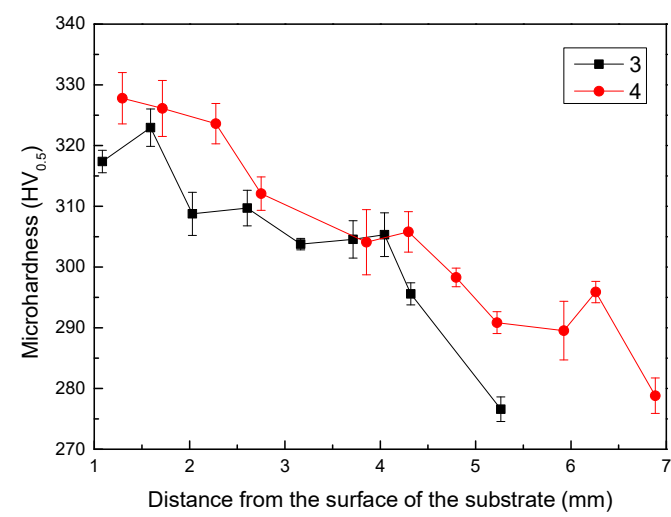

(b)

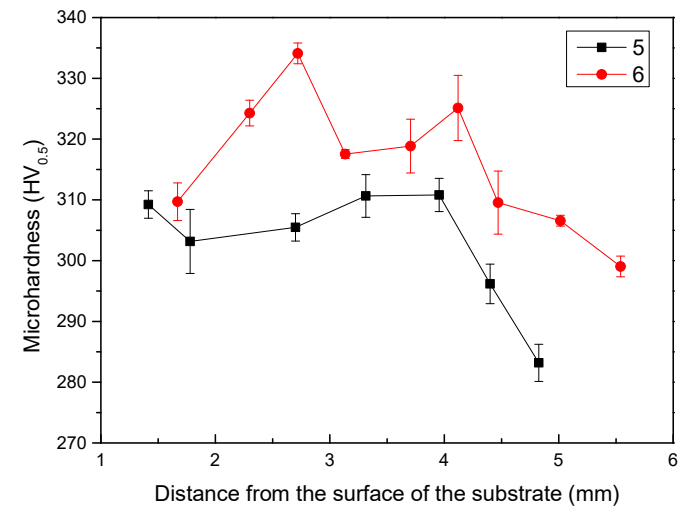

(c)

Figure 12. Microhardness (HV) distribution of 6 groups of the single track along the depth direction from the top surface of the substrate: (a) Sample 1 and 2; (b) Sample 3 and 4; (c) Sample 5 and 6.

\section{Conclusions}

In metal additive manufacturing of non-interlayer cooling deposition, the macro-size is difficult to control due to the heat accumulation effect. In this work, the interlayer cooling effect was studied by cladding Ni-based coatings on a ductile iron substrate with different powers. By comparing the microstructures and mechanical properties of the Ni-based alloy cladding on ductile iron with and without interlayer cooling, the following conclusions can be drawn:

- With the development of the cladding process, due to the heat storage effect and remelting, the increase in thickness becomes smaller and smaller. Thus, it becomes more difficult to control the macro-size. However, through the interlayer cooling, the thickness increment between layers will be more uniform, and the dilution rate will be smaller.

- Compared with the non-interlayer cooling deposition, due to better heat dissipation, the interlayer cooling deposited specimens have less impurities and more uniform microstructure. Meanwhile, the average grain size is refined, and the dendrite growth is inhibited. In addition, the difference between the two grain sizes will become more and more significant with the increase of the power. At the same time, the increase of the power makes the grain sizes of non-interlaminar cooling samples increase significantly, while the grain sizes of interlayer cooling samples have no significant change. It plays an important role in improving the use of the power and has a positive impact on its corresponding mechanical properties.

- Compared with the non-interlayer cooling deposition, the interlayer cooling deposition specimens have higher hardness. Furthermore, as the power increases, the difference between the hardness of the two specimens becomes larger. 
Author Contributions: Investigation, Z.Z. and W.H.; Data Curation, J.C. and F.X.; Writing-Original Draft Preparation, Y.H.; Writing-Review and Editing, Y.L. and J.S.; Project Administration, Y.H.; Funding Acquisition, J.Y. and Y.H. All authors have read and agreed to the published version of the manuscript.

Funding: This research was funded by the National Key Research and Development Program of China (Grant No. 2017YFB1103200), Natural Science Foundation of Jiangsu Universities (Grant Nos. 17KJB510031, BK20190712), Six Talent Peaks Project in Jiangsu Province (Grant No. TD-GDZB-009) and Postgraduate Research \& Practice Innovation Program of Jiangsu Province (Grant No. KYCX19_0814), Nantong Key Laboratory of 3D printing technology and Application CP12016002.

Conflicts of Interest: The authors declare no conflict of interest.

\section{References}

1. Labrecque, C.; Gagné, M. Ductile iron: Fifty years of continuous development. Can. Metall. Qual. 1998, 37, 343-378.

2. Zeng, D.W.; Xie, C.S.; Yung, K.C. Investigation of laser surface alloying of copper on high nickel austenitic ductile iron. Mater. Sci. Eng. 2003, 333, 23-231. [CrossRef]

3. Li, R.F.; Qiu, Y.; Zhang, Q.C. Finite element simulation of temperature and stress field for laser cladded nickel-based amorphous composite Coatings. Coatings 2018, 8, 336. [CrossRef]

4. Huang, Y.J.; Zeng, X. Investigation on cracking behavior of Ni-based coating by laser-induction hybrid cladding. Appl. Surf. Sci. 2010, 256, 5985-5992. [CrossRef]

5. Zhou, S.; Dai, X.; Zeng, X. Effects of processing parameters on structure of Ni-based WC composite coatings during laser induction hybrid rapid cladding. Appl. Surf. Sci. 2009, 255, 8494-8500. [CrossRef]

6. Huang, S.W.; Nolan, D.; Brandt, M. Pre-placed WC/Ni clad layers produced with a pulsed Nd: YAG laser via optical fibers. Surf. Coat. Technol. 2003, 165, 26-34. [CrossRef]

7. Mughal, M.P.; Fawad, H.; Mufti, R. Finite element prediction of thermal stresses and deformations in layered manufacturing of metallic parts. Acta Mech. 2006, 183, 61-79. [CrossRef]

8. Mughal, M.P.; Fawad, H.; Mufti, R. Numerical thermal analysis to study the effect of static contact angle on the cooling rate of a molten metal droplet. Numer. Heat Transf. A 2006, 49, 95-107. [CrossRef]

9. Denlinger, E.R.; Heigel, J.C.; Michaleris, P. Effect of inter-layer dwell time on distortion and residual stress in additive manufacturing of titanium and nickel alloys. J. Mater. Process. Technol. 2015, 215, 123-131. [CrossRef]

10. Chen, Y.; Lu, F.; Zhang, K. Dendritic microstructure and hot cracking of laser additive manufactured Inconel 718 under improved base cooling. J. Alloys Compd. 2016, 670, 312-321. [CrossRef]

11. Weng, F.; Yu, H.J.; Chen, C.Z. Effect of process parameters on the microstructure evolution and wear property of the laser cladding coatings on Ti-6Al-4V alloy. J. Alloys Compd. 2017, 692, 989-996. [CrossRef]

12. Liu, F.C.; Lin, X.; Yang, G.L. Microstructures and mechanical properties of laser solid formed nickel base superalloy Inconel 718 prepared in different atmospheres. J. Metals 2010, 46, 1047-1054.

13. Cheng, Y.H.; Cui, R.; Wang, H.Z. Effect of processing parameters of laser on microstructure and properties of cladding 42CrMo steel. Int. J. Adv. Des. Manuf. Technol. 2018, 96, 1715-1724. [CrossRef]

14. Radhakrishnan, B.; Thompson, R.G. Solidification of the nickel-base superalloy 718: A phase diagram approach. Metall. Trans. A 1989, 20, 2866-2868. [CrossRef]

15. Spencer, J.; Dickens, P.; Wykes, C. Rapid prototyping of metal parts by 3D welding. Inst. Mech. Eng. B J. Eng. Manuf. 1998, 212, 175-181. [CrossRef]

16. Song, W.L.; Zhu, P.D.; Cui, K. Effect of Ni content on cracking susceptibility and microstructure of laser-clad Fe-Cr-Ni-B-Si alloy. Surf. Coat. Technol. 1996, 80, 279-282.

17. Qian, M.; Lim, I.C.; Chen, Z.D. Parametric studies of laser cladding processes. J. Mater. Process. Technol. 1997, 63, 590-593. [CrossRef]

18. Liu, H.X.; Wang, C.Q.; Zhang, X.W. Improving the corrosion resistance and mechanical property of 45 steel surface by laser cladding with Ni60CuMoW alloy powder. Surf. Coat. Technol. 2013, 228, S296-S300. [CrossRef]

19. Ke, L.; Zhu, H.; Yin, J. Effects of peak laser power on laser micro sintering of nickel powder by pulsed Nd:YAG laser. Rapid Prototyp. J. 2014, 20, 328-335. [CrossRef]

20. Singh, A.; Dahotre, N.B. Laser in situ synthesis of mixed carbide coating on steel. Mater. Sci. 2004, 39, 4553-4560. [CrossRef] 
21. Lima, M.S.F.; Ladario, F.P.; Riva, R. Microstructural analyses of the nanoparticles obtained after laser irradiation of Ti and W in ethanol. Appl. Surf. Sci. 2006, 252, 4420-4424. [CrossRef]

22. Gao, W.; Zhang, Z.; Zhao, S. Effect of a small addition of Ti on the Fe-based coating by laser cladding. Surf. Coat. Technol. 2016, 291, 423-429. [CrossRef]

(C) 2020 by the authors. Licensee MDPI, Basel, Switzerland. This article is an open access article distributed under the terms and conditions of the Creative Commons Attribution (CC BY) license (http://creativecommons.org/licenses/by/4.0/). 